\title{
PREVALENCIA DE ANTICORPOS NEUTRALIZANTES CONTRA O HERPESVÍRUS BOVINO TIPO 1, DECORRENTE DE INFECÇÃO NATURAL, EM REBANHOS COM DISTÚRBIOS REPRODUTIVOS ${ }^{1}$
}

\author{
PREVALENCE OF NEUTRALIZING ANTIBODIES AGAINST BOVINE HERPESVIRUS \\ TYPE 1, DUE NATURAL INFECTION, IN HERDS WITH REPRODUCTIVE PROBLEMS
}

\author{
Kerlei Cristina Médici ${ }^{2}$ Amauri Alcindo Alfieri ${ }^{3} \quad$ Alice Fernandes Alfieri $^{3}$
}

- NOTA -

RESUMO

A detecção de anticorpos anti-Herpesvírus Bovino tipo 1 (BHV-1) foi realizada, através da técnica de soroneutralização, em 1235 amostras de soro de bovinos adultos, nãovacinados contra Rinotraqueíte Infecciosa Bovina. As amostras de soro analisadas foram colhidas em 81 rebanhos, com histórico de problemas reprodutivos, incluindo animais com aptidão para carne e leite, provenientes de 30 municípios do Estado do Paraná. Na amostragem proveniente de rebanhos leiteiros, 41,9\% (409/977) das amostras de soro e 90,5\% (57/63) dos rebanhos foram considerados positivos. Em bovinos de corte, o índice de soropositividade foi de 50,8\% (131/258) e 100\% (18/18) para amostras de soro e rebanhos, respectivamente. As freqüencias de $43,7 \%$ (540/1235) de animais e 92,6\% (75/81) de rebanhos soropositivos demonstram que as infecções por BHV-1 apresentam-se amplamente disseminadas nas regiões estudadas.

Palavras-chave: bovinos, Herpesvirus bovino tipo 1, sorologia, soroneutralização, problemas reprodutivos.

\section{SUMMARY}

Serum samples of 1235 adult cattle not infectious bovine rhinotracheitis-vaccinated were analyzed by serum neutralization technique for Bovine Herpesvirus type 1 ( $B H V-1$ ) antibodies. The samples were collected from 81 beef and dairy herds presenting reproductive problems, at 30 counties of Parana State, Brazil. In dairy herds 41.9\% (409/977) of the serum samples and $90.5 \%$ (57/63) of the herds were positives. In beef herds the index of positives was $50.8 \%$ (131/258) and $100 \%$ (18/18) for serum samples and herds, respectively. The total positive frequency of serum samples (43.7\%) and herds (92.6\%) show that BHV-1 infections has a wide dissemination in the studied region.
Key words: bovine, Bovine herpesvirus type 1, serology, serum neutralization, reproductive problems.

O Herpesvírus Bovino tipo 1 (BHV-1) é considerado um dos principais patógenos de bovinos, sendo responsável por grandes prejuízos econômicos à exploração pecuária. Clinicamente, as infecções pelo BHV-1 manifestam-se sob formas distintas, entre as quais se destacam a respiratória (Rinotraqueíte Infecciosa Bovina -IBR-), genital (Vulvovaginite / Balanopostite Pustular Infecciosa -IPV/IPB-), sistêmica, nervosa e reprodutiva (STRAUB, 1990; WYLER et al., 1990).

As diferentes formas clínicas observadas nas infecções pelo BHV-1, somente foram melhor compreendidas após análises antigênicas e moleculares realizadas em amostras virais isoladas de animais expressando sinais clínicos distintos. A utilização de anticorpos monoclonais, técnicas de hibridização e análises do genoma viral com enzimas de restrição possibilitaram a identificação de subtipos virais. Embora não seja regra, a maioria dos isolamentos víricos, obtidos de problemas respiratórios, reprodutivos e conjuntivites, correspondem ao subtipo BHV-1.1 e as infecções genitais (IPV/IPB), aos subtipos BHV-1.2 $\mathrm{A}$ e BHV-1.2 $2_{\mathrm{B}}$. Os BHV isolados de casos de encefalites foram recentemente reclassi-

\footnotetext{
${ }^{1}$ Apoio financeiro: $\mathrm{CNPq}, \mathrm{CPG} / \mathrm{UEL}$

${ }^{2}$ Médico Veterinário, aluno do Programa de Mestrado em Sanidade Animal, DMVP/CCA/UEL.

${ }^{3}$ Professores do Departamento de Medicina Veterinária Preventiva (Laboratório de Virologia Animal)/CCA - Universidade Estadual de Londrina, Londrina - PR., 86051-990. E-mail: alfieri @ uel.br. Autor para correspondência.
} Recebido para publicação em 17.09.98. Aprovado em 11.08.99 
ficados como BHV tipo 5 (METZLER et al., 1985; MAGYAR et al., 1993).

Uma importante característica biológica dos vírus da subfamília Alphaherpesvirinae, na qual está incluído o BHV-1, é o estabelecimento de latência em gânglios sensoriais. Nessa situação, os animais infectados tornam-se portadores inaparentes, com episódios esporádicos de reexcreção viral e potenciais transmissores do vírus. Essa característica determina a perpetuação e disseminação da infecção pelo BHV-1 no rebanho (PASTORET et al., 1982).

As infecções pelo BHV-1 contribuem ainda, significativamente, com reduções nos índices de reprodução dos rebanhos infectados. Na dependência do período gestacional, as fêmeas bovinas podem apresentar mortalidade embrionária precoce e/ou tardia, com repetição de cios a intervalos regulares ou irregulares; abortos, predominantemente caracterizados a campo, a partir do quarto mês de gestação; natimortos e o nascimento de animais fracos. Além do embrião e feto, o aparelho reprodutivo também é bastante susceptível aos efeitos das infecções pelo HVB, as quais podem determinar vulvovaginites, endometrites, salpingites e ooforites, que apresentam como principal conseqüência a infertilidade temporária (BOWEN et al., 1985; CHIANG et al., 1990; KIRKBRIDE, 1985; MILLER, 1991).

Evidências sorológicas e mesmo etiológicas demonstram a presença, bem como a alta freqüência, das infecções pelo BHV-1 nos rebanhos brasileiros. A porcentagem de animais sororreagentes varia consideravelmente entre os levantamentos epidemiológicos porém, na maioria dos trabalhos, os índices de animais soropositivos são superiores ou estão muito próximos a $50 \%$ da amostragem analisada (MUELLER et al., 1981; VIDOR et al., 1995).

Com relação aos rebanhos paranaenses, os dados indicativos da presença de infecções pelo BHV-1 ainda são escassos. Na expectativa de contribuir com informações epidemiológicas, diante de uma situação específica, este estudo objetivou, primordialmente, a avaliação da freqüência de soroconversão ao BHV-1 em animais e plantéis com histórico de problemas reprodutivos compatíveis, entre outras enfermidades, com as infecções por BHV-1.

No período de junho de 1995 a junho de 1996, foram colhidas 1235 amostras de sangue em 81 rebanhos bovinos, incluindo animais com aptidão para carne e leite, em 30 municípios do Estado do Paraná. Todas as amostras foram provenientes de animais adultos, não vacinados contra IBR e de rebanhos com rígido controle de brucelose, que inclui a vacinação de todas as bezerras e exames sorológicos periódicos. Os soros sangüíneos, obtidos após a formação do coágulo, foram centrifugados, inativados a $56^{\circ} \mathrm{C}$ e estocados a $-20^{\circ} \mathrm{C}$ até a execução do teste sorológico.

A amostragem foi subdividida em duas categorias, sendo denominada de "REBANHO PARCIAL" as amostras provenientes de animais que apresentaram distúrbios reprodutivos. Nessa situação, foram colhidas em média sete amostras por plantel. Na categoria "REBANHO TOTAL" estão incluídas as amostras provenientes de plantéis com baixo índice reprodutivo, onde $100 \%$ dos animais em fase reprodutiva foram analisados. A tabela 1 apresenta o número total de amostras de soros bovinos, colhidas em propriedades rurais no Estado do Paraná, distribuídos de acordo com a metodologia de colheita, aptidão dos animais e o número de propriedades rurais

A detecção de anticorpos contra BHV-1 foi realizada de acordo com a microtécnica de soroneutralização (SN) descrita por BRITSCH, 1978. Após prévia inativação a $56^{\circ} \mathrm{C} / 30 \mathrm{~min}$, diluições dos soros, de 1:2 a 1:64, realizadas em meio Dulbecco's Modified Eagle's (DMEM, SIGMA, EUA) foram distribuídas em microplacas de 96 cavidades e incubadas com 100 TCID 50\% do protótipo Los Angeles de BHV-1. Após incubação por uma hora a $37^{\circ} \mathrm{C}$, uma suspensão de $4 \times 10^{4}$ células MDBK (Madin Darby Bovine Kidney) em meio DMEM/cavidade foi adicionada e as placas incubadas a $37^{\circ} \mathrm{C} \mathrm{em}$ atmosfera de $5 \%$ de $\mathrm{CO}_{2}$ por três dias. Foram consideradas positivas as amostras que inibiram $100 \%$ do efeito citopático (ECP) de BHV-1 nas diluições $\geq$ $1: 4$.

A tabela 2 apresenta os resultados da avaliação sorológica para BHV-1, realizada pela técnica de SN, em 1235 soros de bovinos, distribuídos de acordo com a aptidão dos animais e tipo de amostragem. Independentemente da aptidão dos animais (leite/corte) e do tipo da amostragem (REBANHO PARCIAL/TOTAL), a freqüência média encontrada de $43,7 \%$ de animais sororreagentes ao BHV-1, bem como de $92,6 \%$ de rebanhos com animais soropositivos, pode ser considerada alta. Por se tratar de animais sabidamente não-vacinados contra IBR, esse índice, originado por infecções naturais pelo BHV-1, demonstra que essa infecção está amplamente instalada nos rebanhos avaliados. Como as primoinfecções, com freqüência, são acompanhadas de manifestações clínicas, esse alto índice de animais e rebanhos soropositivos indica que a grande maioria das infecções por BHV-1 não são diagnosticadas ou são confundidas com outras enfermidades infectocontagiosas que determinam sinais clínicos semelhantes. Mesmo não tendo sido avaliadas outras 
Tabela 1 - Distribuição das amostras de soro bovino utilizadas para o diagnóstico sorológico da infecção por Herpesvírus Bovino tipo 1 em rebanhos do Estado do Paraná / Brasil, de acordo com o tipo de amostragem e aptidão dos animais.

\begin{tabular}{cccc}
\hline $\begin{array}{c}\text { APTIDÃO DOS } \\
\text { ANIMAIS }\end{array}$ & $\begin{array}{c}\text { TIPO DE } \\
\text { AMOSTRAGEM }\end{array}$ & $\begin{array}{c}\text { NÚMERO DE } \\
\text { PROPRIEDADES }\end{array}$ & $\begin{array}{c}\text { NÚMERO DE } \\
\text { ANIMAIS }\end{array}$ \\
\hline \multirow{2}{*}{ LEITE } & REBANHO PARCIAL & 49 & 341 \\
& REBANHO TOTAL & 14 & 636 \\
& Subtotal & 63 & 977 \\
CORTE & REBANHO PARCIAL & 12 & 91 \\
& REBANHO TOTAL & 6 & 167 \\
& Subtotal & 18 & 258 \\
\hline \multirow{2}{*}{ TOTAL } & & 81 & 1235 \\
\hline
\end{tabular}

maior período. Com isso, ao longo do tempo, assim como em bovinos de aptidão leiteira, a infecção por BHV-1 apresenta tendência a tornar-se endêmica também em rebanhos de corte, o que pode justificar a alta freqüência de sororreagentes encontrada no presente levantamento.

$\mathrm{Na}$ amostragem denominada "PLANTEL PARCIAL", foi encontrado um índice significativo $(\mathrm{P}<0,05)$ de animais sororreagentes entre os bovinos de corte $(61,5 \%)$, em relação aos bovinos de aptidão leiteira $(39,3 \%)$. Em bovinos de alta produção de leite, os níveis nutricionais, particularmente os desequilíbrios, podem exercer influência direta nos índices reprodutivos (PRITCHARD, 1985). O menor índice de resultados de sorologia positiva para

causas de distúrbios reprodutivos, incluindo as causas não-infecciosas e mesmo infecciosas como leptospirose, diarréia viral bovina e micoplasmoses, entre outras, esses resultados, obtidos de animais e/ou plantéis com controle de brucelose, sugerem que, na presença de problemas reprodutivos, a freqüência de sororeagentes ao BHV-1 pode ser superior à encontrada em levantamentos não dirigidos.

A freqüência total de $50,8 \%$ de animais soropositivos ao BHV-1, encontrada em reprodutores de corte, foi significativamente superior $(\mathrm{P}<$ $0,05)$ à detectada em animais de aptidão leiteira $(41,9 \%)$. Esse resultado demonstra que, no período e regiões estudados, o BHV-1 também esteve presente em alta freqüência nos plantéis de bovinos de corte.

De forma geral, as práticas de manejo intensivo, a que são submetidos os bovinos de aptidão leiteira, possibilitam uma maior facilidade de transmissão de várias enfermidades infecciosas, em relação aos bovinos criados extensivamente, como é o caso da maioria dos reprodutores de gado de corte. Porém, a latência viral induzida pelo BHV-1 implica que animais portadores assintomáticos, com episódios de reexcreção viral, possam ser responsáveis pela manutenção e perpetuação desse vírus nos rebanhos, independentemente do tipo de manejo. Com a infecção instalada, as características diferenciadas de manejo, intensivo ou extensivo, somente poderão exercer influência na velocidade da transmissão, não contribuindo com a interrupção da cadeia epidemiológica. A menor taxa de reposição de reprodutores nos plantéis de corte, em comparação à observada em rebanhos leiteiros, também pode influenciar nas taxas de infecção, devido, principalmente, à permanência de animais soropositivos no plantel por um o BHV-1 (39,3\%), observado na amostragem "REBANHO PARCIAL" de bovinos com aptidão leiteira, sugere que outras causas infecciosas não avaliadas, e mesmo não-infecciosas, possam ter sido responsáveis pelos problemas reprodutivos verificados nos animais desse grupo.

As carências nutricionais podem exercer menor influência nos índices reprodutivos em bovinos de corte, criados extensivamente, como a maioria dos animais incluídos neste estudo. Com isso, particularmente nas situações em que os problemas reprodutivos atingem de forma rápida uma grande proporção dos animais em rebanhos de corte, devese avaliar a probabilidade de etiologia infecciosa. Mesmo não tendo sido consideradas outras etiologias, o índice de $61,5 \%$ de animais sororreagentes sugere uma provável participação do BHV-1 nos distúrbios reprodutivos descritos nesses animais.

As técnicas sorológicas, empregadas neste e na grande maioria dos trabalhos relativos ao diagnóstico de IBR, fornecem apenas uma indicação do grau de infecção em um determinado rebanho ou mesmo região. Porém, apenas os dados sorológicos não possibilitam uma correlação direta entre os problemas clínicos encontrados e o índice de soroconversão. A elaboração do diagnóstico etiológico definitivo somente pode ser obtida através do isolamento viral em cultivo celular ou a detecção de antígenos e/ou genoma viral, a partir de material biológico colhido de animais expressando sinais clínicos (WYLER $\boldsymbol{e t}$ al., 1990). Apesar de não ser objetivo deste trabalho, em algumas situações, foi possível a correlação da evidência sorológica da infecção com problemas clínicos encontrados, através do isolamento do BHV-1 em oito casos de vul- 
Tabela 2 - Distribuição dos resultados do diagnóstico sorológico, pela técnica de soroneutralização, da infecção por Herpesvírus Bovino tipo 1 em rebanhos do Estado do Paraná, Brasil/1996.

\begin{tabular}{ccccccccc}
\hline \multirow{2}{*}{$\begin{array}{c}\text { APTIDÃO DOS } \\
\text { ANIMAIS }\end{array}$} & TIPO DE AMOSTRAGEM & \multicolumn{3}{c}{ REBANHOS } & \multicolumn{3}{c}{ AMOSTRAS (SOROS) } \\
\cline { 3 - 8 } & & POS $(\%)$ & NEG $(\%)$ & TOTAL & POS $(\%)$ & NEG (\%) & TOTAL \\
\hline \multirow{2}{*}{ LEITE } & REBANHO PARCIAL & $44(89,7)$ & $5(10,2)$ & 49 & $134(39.3)$ & $207(60,7)$ & 341 \\
& REBANHO TOTAL & $13(92,8)$ & $1(7,2)$ & 14 & $275(43.2)$ & $361(56,8)$ & 636 \\
& Subtotal & $57(90,5)$ & $6(9,5)$ & 63 & $409(41.9)$ & $568(58,1)$ & 977 \\
& REBANHO PARCIAL & $12(100)$ & 0 & 12 & $56(61.5)$ & $35(38,5)$ & 91 \\
CORTE & REBANHO TOTAL & $6(100)$ & 0 & 6 & $75(44.9)$ & $92(55,1)$ & 167 \\
& Subtotal & $18(100)$ & 0 & 18 & $131(50.8)$ & $127(49,2)$ & 258 \\
\hline \multirow{2}{*}{ TOTAL } & & $75(92,6)$ & $6(7,4)$ & 81 & $540(43.7)$ & $695(56,3)$ & 1235 \\
\hline
\end{tabular}

vovaginite e três casos de abortos (dados não mostrados).

Os dados obtidos neste trabalho demonstram claramente a importância da inclusão das infecções por BHV-1 no diagnóstico diferencial de várias patologias bovinas, particularmente nos distúrbios reprodutivos com características infecciosas. O desenvolvimento e a ampliação no uso de técnicas de diagnóstico etiológico, sensíveis e específicas, poderão contribuir significativamente para elucidação da real importância clínica dessa virose, bem como possibilitar o diagnóstico diferencial, tanto nos problemas reprodutivos em bovinos quanto em outras formas de manifestação clínica. Com isso, de forma consciente e racional, medidas de controle e profilaxia poderão não somente serem adotadas, como também, periodicamente, monitoradas.

\section{REFERÊNCIAS BIBLIOGRÁFICAS}

BOWEN, R.A., ELSDEN, R.P., SEIDEL, S.E. Herpesvirus bovine type1-abortion. American Journal Veterinary Research, v.46, p.1095-1097, 1985.

BRITSCH,V. The modification of the infectious bovine rhinotracheitis virus serum neutralization test. Acta Veterinaria Scandinava, v.19, p.497-505, 1978.

CHIANG, B.C., NUSBAUN, K.E., STRINGFELLOW, D.A., $\boldsymbol{e}$ al. The effect of infectious bovine rhinotracheitis vaccine on reproductive efficiency in cattle vacinated during estrus. Theriogenology, v.33, n.25, p.603-604, 1990

KIRKBRIDE, C.A. Mananging and outbreak of liverstock abortion - 2:diagnosis and control of bovine abortion. Veterinary Medicine, v.80, n.5, p.70-79, 1985.
MAGYAR, G., TANYI, J., HORNYÁK, A., et al. Restriction endonuclease analysis of Hungarian bovine herpesvirus isolates from different clinical forms of IBR/IPV and encephalitis. Acta Veterinaria Hungarica, v.4, n.1-2, p.159$170,1993$.

METZLER, A.E., MATILE, H., GASSMANN,V., et al. European isolates of bovine herpesvirus 1: a comparison of restriction endonuclease sites, polypetides and reactivity with monoclonal antibodies. Archives of Virology, v.85, p.57-59, 1985.

MILLER, J.M. The effects of IBR virus infection on reproductive function of cattle. Veterinary Medicine, v.86, n.1, p.95-98, 1991.

MUELLER, S.B.K., IKUNO, A.A., MACHADO, J.S., et al. Prevalência de anticorpos contra o vírus da rinotraqueíte infecciosa bovina/vulvovaginite pustular infecciosa (IBR/IPV) em bovinos do Estado de São Paulo. O Biológico, v.47, n.2, p.55-59, 1981 .

PASTORET, P., THIRY, E., BROCHIER, B., et al. Bovine Herpesvirus 1 infection of cattle pathogenesis, latency, consequences of latency. Annual Record Veterinary, v.13, p.221-235, 1982 .

PRITCHARD, G. Diagnosis the cause of bovine abortion. In Practice, v.12, n.3, p.92-97, 1985.

STRAUB, O.C. Infectious bovine rhinotracheitis virus. In: DINTER \& MORIM (Eds). Virus infections of ruminants. Amsterdam : Elsevier Science Publishers, 1990. p.71-108.

VIDOR, T., HAEFEN, D.C., LEITE, T.E., et al. Herpesvirus Bovino tipol (BHV 1). Sorologia de rebanhos com problemas reprodutivos. Ciência Rural, v.25, n.3, p.421-424, 1995.

WYLER, R., ENGELS, M., SCHWYZR, M. Infectious bovine rhinotracheitis / vulvovaginites (BHV-1). In: Herpesvirus diseases of cattle, horses and pigs. London : Academic, 1990. p.01-07.

Ciência Rural, v. 30, n. 2, 2000. 